\title{
Launching the Feature Article series
}

\author{
George Haller • Walter Lacarbonara
}

Published online: 10 December 2020

(C) The Author(s), under exclusive licence to Springer Nature B.V. 2020, corrected publication 2023

We are delighted to announce the new Feature Article series of Nonlinear Dynamics. This series will be a collection of invited contributions from leading experts in the general area of applied nonlinear dynamical systems. Different from traditional reviews of established research areas, Feature Articles will provide technical introductions to emerging research areas of broad current interest and potential societal impact, with a distinct clarity and breadth of exposition. Submissions to this new series are solicited and handled in a fast-track peer-review process by a dedicated Feature Editor.

In the current NODY issue, we are excited to publish our first Feature Article on nonlinear predictive control for COVID-19 management. This contribution was written by a group of authors led by Prof. Gergely Röst of the University of Szeged, a mathematical epidemiology expert and national COVID task force member.

We are likewise delighted to announce the upcoming publication of the next Feature by Prof. Francisco J. Beron-Vera on nonlinear dynamics of inertial particles in the ocean, from drifters and floats up to marine debris.

George Haller, Feature Editor

Walter Lacarbonara, Editor-in-Chief

Publisher's Note Springer Nature remains neutral with regard to jurisdictional claims in published maps and institutional affiliations.
G. Haller

Institute for Mechanical Systems, ETH Zurich,

8092 Zurich, Switzerland

e-mail: georgehaller@ethz.ch

W. Lacarbonara $(\bowtie)$

Department of Structural Engineering, Sapienza

University of Rome, 00164 Rome, Italy

e-mail: walter.lacarbonara@uniroma1.it 